\title{
Urgent Care in the Dental School Setting: Analysis of Current Environment and Future Challenges in Emergency Dental Education
}

\author{
Karen K. Tiwana, D.D.S.; Kimberly J. Hammersmith, B.A.; Valerie A. Murrah, \\ D.M.D., M.S., M.A.Ed.
}

Abstract: Urgent dental care education is a critical aspect of the D.D.S. curriculum as dental students must be adequately prepared to face real-world dental emergency challenges in practice. Dental emergency education is likely the most variable component of the dental curriculum. To assess potential differences in emergency education, a sixteen-question survey was sent to directors of urgent care of all fifty-six U.S. dental schools addressing clinic operation, demographics, treatment, integration into the D.D.S. curriculum, and provision of care for indigent populations. The response rate was 88 percent. Results indicate a need for earlier integration of urgent dental care education into the D.D.S. curriculum, more pediatric emergency experiences for D.D.S. students, and a more rigorous academic approach in assessing student competency while on rotation in the urgent care service. In addition, access to emergency dental care has become increasingly difficult for indigent populations due to lack of state-supported funds; further exploration of sources of external funding for such care is warranted.

Dr. Tiwana is Director of Urgent Care and Clinical Assistant Professor, Department of Diagnostic Sciences and General Dentistry; Ms. Hammersmith is a D.D.S. student; and Dr. Murrah is Professor and Chair, Department of Diagnostic Sciences and General Dentistry - all at the University of North Carolina at Chapel Hill School of Dentistry. Direct correspondence and requests for reprints to Dr. Karen K. Tiwana, Department of Diagnostic Sciences and General Dentistry, University of North Carolina School of Dentistry, CB \#7450, Chapel Hill, NC 27599; 919-843-4841 phone; 919-966-0705 fax; karen_tiwana@dentistry.unc.edu.

Key words: urgent dental care, emergency dental care, access to care, D.D.S. curriculum, indigent care, pediatric dental emergencies

Submitted for publication 5/11/06; accepted 10/27/06

$\mathrm{T}$ The ability to deliver emergency dental treatment in a timely and caring manner while simultaneously educating dental students concerning the art and science associated with that treatment has always been a challenge for educators and students in the institutional setting. The fact that urgent care services are frequently the site of first encounters with a dental school setting for a number of patients makes it paramount that these clinics represent the epitome of optimal professional interaction and service. Furthermore, urgent care services may be the only source, or the major source, of education for D.D.S. students concerning the management of acute pain, trauma, and swelling, as well as acute failure of restorations or prostheses.

While no dental educator would dispute the need for a systematic focus on the approach to urgent care in the dental school setting, very little has been written on the subject. Sharav et al. in 1973 discussed emergency patients as a source for learning oral diagnosis ${ }^{1}$; Gates and Durchslag reviewed the issue of triage in the management of dental emergency patients in $1978^{2}$; and Bauman et al. addressed afterhours emergency policies in dental schools in 1998. ${ }^{3}$ A brief communication concerning the availability of emergency dental services at dental institutions was reported by Ferraro et al. in $1982 .{ }^{4}$

For our study, a sixteen-question survey was sent to directors of urgent care at all U.S. dental schools with the purpose of providing an updated overview of current practices in the delivery of urgent care services at the D.D.S. student level, as well as an overview of the extent to which specific educational objectives are addressed in the clinical setting. Analysis and discussion of the survey responses will help educators address the challenges associated with emergency dental education and develop a more formal standardized curriculum for predoctoral students.

\section{Methods}

To assess urgent care services at U.S. dental schools, a sixteen-question survey (Figure 1) was created to gather information relevant to the operation, treatment, and integration of urgent dental care into the D.D.S. curriculum, as well as clinic demographics and indigent care. The survey consisted of seven single-answer multiple-choice, six multiple-answer 
1. How are active student patient emergencies handled? By the assigned D.D.S. student

In the urgent care clinic by a student on rotation

Both

- Other. Please specify

2. Approximately how many dental emergency patients not of record and/or walk-ins are seen per month in the emergency clinic?
Less than 100
200-300
— 100-200
300-400
400-500
More than 500

3. Approximately what percentage of your patient population in the urgent care service is referred to Endodontics?

$0-25 \%$
$25-50 \%$
$50-75 \%$

$25-50 \%$

More than $75 \%$

4. Approximately what percentage of your patient population in the urgent care service is referred to Oral and Maxillofacial Surgery?

$$
\begin{aligned}
& 0-25 \% \\
& -25-50 \%
\end{aligned}
$$
$50-75 \%$

More than $75 \%$

5. Is treatment offered in the urgent care clinic, or is the patient triaged for treatment elsewhere following diagnostic work-up? Please indicate with a $U$ (Urgent Care) or a $T$ (Triaged) or a B (Both) as to how each of the procedures below is managed. Extractions

Pulpotomies

Pulpectomies Sedative fillings

Permanent fillings

Acrylic flippers

_ Partial and denture repairs
Provisional restorations

Scaling and root planing

_ Other: Please list

6. Is your emergency service open during student break and holidays?

Yes

No

7. If you answered "Yes" in question 6, how is the clinic staffed? Please check all that apply. Full-time faculty _ Postgraduate residents (any specialty) Part-time faculty $\quad$ Volunteer students (paid or unpaid)

Other: Please list

8. On average, how many hours per week is your emergency clinic operational? $0-5$ hours
$10-15$ hours
20-30 hours
5-10 hours
$15-20$ hours
- More than 30 hours

9. In terms of the supervising dentist(s), what facets of dentistry are represented on the clinic floor in the urgent care clinic? Please check all that apply.

_ General Dentistry

Endodontics

Oral and Maxillofacial Surgery

Oral and Maxillofacial Radiology
Oral and Maxillofacial Pathology

Oral Medicine

Orthodontics

Dental Public Health
Periodontics

- Pediatric Dentistry

_ Prosthodontics

10. How many required days do the D.D.S. students rotate in the urgent care clinic? days

11. What level of student rotates into the urgent care clinic? Please circle all that apply.

_ Freshman

_ Junior

_ Sophomore

— Senior

12. Are there any requirements (clinical/didactic) for the rotation students? Please describe briefly.

$\begin{array}{ll}\text { Clinical } & \text { Competency } \\ \text { - Didactic None }\end{array}$

13. Does your school's urgent care clinic address indigent care? Please circle all that apply.

— We only take paying patients _ Other

14. What do you feel is a dental school's responsibility towards indigent care?

15. How many students provide care during any single clinic session in the urgent care clinic?

$\begin{array}{ll}\text { One } & \text { Three } \\ \text { Two } & \text { Four }\end{array}$

Four

Five or more

16. Do you schedule patients for specific appointment times in the urgent care clinic, or do you take walk-in patients only? Appointments only Walk-ins only Combination

Figure 1. Survey addressing emergency education practices at U.S. dental schools 
(check all that apply) multiple-choice, one short-answer, and two open-ended questions. One open-ended question requested respondents to describe their opinion of an ideal philosophy for addressing the indigent population's dental needs within a schoolbased dental clinic. The open-ended questions were later categorized for statistical purposes. The survey was mailed in November 2005 to the dean's office at all fifty-six accredited U.S. dental schools, to be forwarded to the director of urgent care services. A stamped, self-addressed return envelope was included in the mailing. The survey was mailed again in March 2005 to nonresponding schools. A total of forty-nine of the fifty-six ( 88 percent) schools responded. All but three schools indicated the school name and the title of the person completing the survey.

\section{Results}

Survey questions were grouped into categories. Percentages are indicative of a positive response to a particular question.

\section{Operation}

In survey responses, 71.4 percent of schools reported that their urgent care services are operational thirty or more hours per week; 26.5 percent of school urgent care services are operational twenty to thirty hours; and 2 percent reported being operational between ten and fifteen hours.

As shown in Figure 2, 6 percent of schools accept only scheduled appointments for emergency patients, 50 percent take walk-ins only, and 44 percent both schedule patients and accept walk-ins. One school specified that pediatric emergencies must be scheduled.

The survey also found that 81.6 percent of urgent care services remain open during school breaks and holidays. Of those, 67.5 percent are staffed by full-time faculty, 57.5 percent by volunteer students (paid or unpaid), 52.5 percent by postgraduate residents of any specialty, 37.5 percent by part-time faculty, and 5 percent by "other." Multiple responses were allowed. "Other" responses included recently licensed D.D.S. graduates in the summer before starting specialty programs and full-time staff dentists (non-faculty). Several schools reported seeing emergency cases at lower capacity during breaks and that patients of record are given priority.

In terms of representation on the clinic floor, General Dentistry is present in 89.8 percent of dental school urgent care services, Endodontics 49 percent, Oral and Maxillofacial Surgery 36.7 percent, Oral Medicine 36.7 percent, Periodontics 32.7 percent, Oral and Maxillofacial Radiology 30.6 percent,

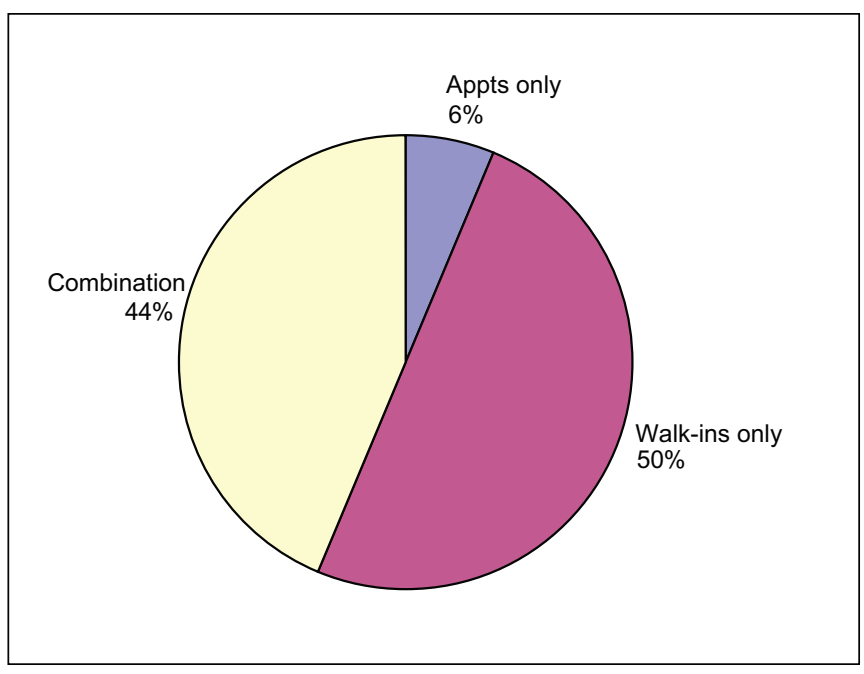

Figure 2. Scheduling modes in dental school urgent care services 
Prosthodontics 30.6 percent, Oral and Maxillofacial Pathology 24.5 percent, Pediatric Dentistry 10.2 percent, Orthodontics 8.2 percent, and Dental Public Health 0 percent. Schools averaged 3.49 types of representing departments. One school reported that all departments share responsibility in staffing the urgent care clinic. Another reported that the clinic is staffed by three staff general practice dentists. A general trend noticed among schools is that specialties are available for consultation.

\section{Treatment}

As shown in Figure 3, the results indicate that providing a diagnosis and subsequent treatment is the core mission of all urgent care services. Respondents reported that obvious limitations such as effective and timely treatment of difficult cases precluded treatment of all emergency patients by the urgent care service alone. Triage is still an effective tool to facilitate treatment for some patients.
Interestingly, two schools indicated that they treat TMD issues in the urgent care service through fabrication of bite splints and physiotherapy. This treatment was not listed among answers on the survey.

The survey responses indicate that there is a definite separation of adult and child emergency care at most dental schools, such that pediatric dental emergencies are instead handled by specialist care.

\section{Integration into the D.D.S. Curriculum}

Approximately 29 percent of active patient emergencies are handled by the assigned D.D.S. student, another 28.6 percent are handled by faculty or students on rotation in the urgent care service, 38.8 percent are handled by both, and 10.2 percent by "Other." Multiple responses were allowed.

For the forty-four responding schools, the average number of required days that D.D.S. students

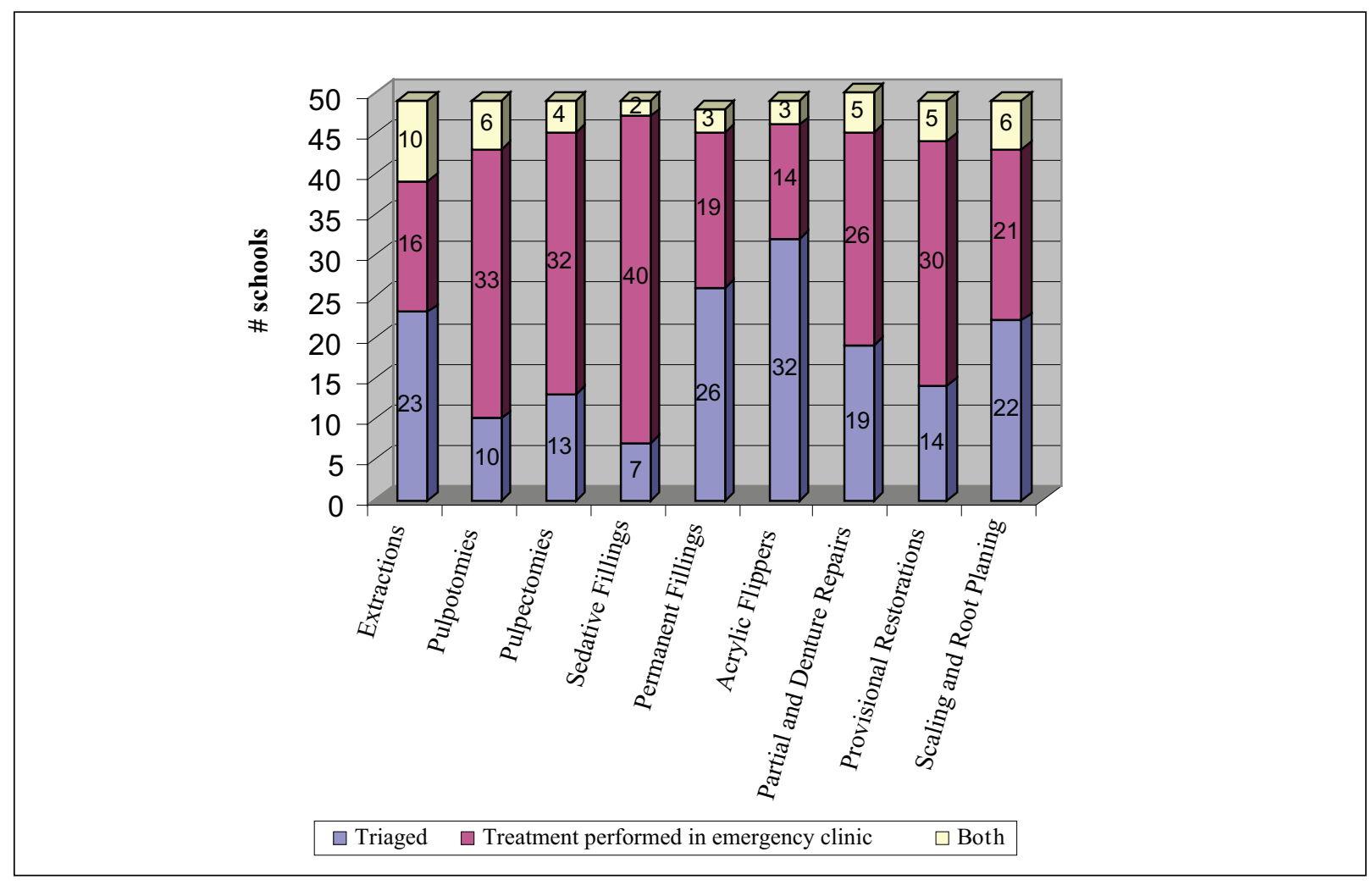

Figure 3. Treatments offered in dental school emergency clinics 


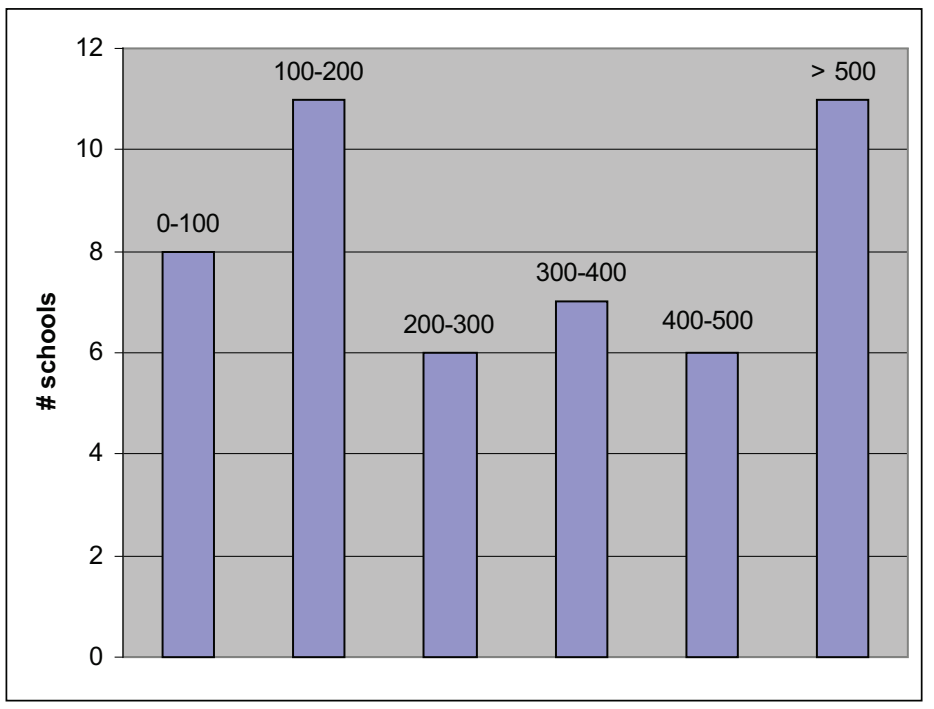

Figure 4. Monthly patient load in dental school urgent care services

rotate in the urgent care service is 14.89 (standard deviation $=8.56$, range 3-40 days). Five schools did not answer this particular question.

All responding schools (100 percent) reported that D.D.S. seniors rotate into the urgent care service. Approximately 78 percent of schools reported that juniors have urgent care rotations, while 8.2 percent and 2 percent of schools also provide urgent care rotations for sophomores and freshmen, respectively. However, these schools noted that freshman and sophomore participation is limited to shadowing/observation.

The survey found that 56.3 percent of schools have five or more students providing care in the urgent care service during any single clinic session; 20.8 percent have four students; 10.4 percent three students; 6.3 percent two students; and 6.3 percent one student. One school reported that one predoctoral student and three AEGD residents provide care.

The survey also found that 65.3 percent of schools have no clinical or didactic requirements for students on rotation in the urgent care service. For this article, we define clinical requirements as expectations beyond attendance such as care for a certain number of patients or performance of a certain number and type of procedures. Didactic requirements are identified by a paper or written exam. Competency exams are patient-based clinical assessment exams. We found that 30.6 percent of schools assess their students by competency evaluations, 6.1 percent have didactic requirements, and 2 percent have clinical requirements. Only one school reported multiple requirements.

\section{Demographics}

Figure 4 displays the numbers of patients seen in dental school urgent care services. In response to the survey, 22.4 percent of schools reported that more than 500 walk-ins or patients not of record are seen in the urgent care service each month. One school said it averages 850 , while 12.2 percent see between 400 and 500 walk-ins per month; 14.3 percent between 300 and 400; 12.2 percent between 200 and 300; 22.4 percent between 100 and 200; and 16.3 percent fewer than 100 .

As shown in Figure 5, 74 percent of schools reported that 0-25 percent of patients seen in the urgent care service are referred to Endodontics; 22 percent of schools reported 25-50 percent; and 4 percent reported 50-75 percent. In addition, 29 percent of schools reported that 0-25 percent of patients seen in the urgent care service are referred to Oral and Maxillofacial Surgery, while 37 percent of schools reported 25-50 percent, 22 percent reported 50-75 percent, and 12 percent reported 75-100 percent. 


\section{Endodontics}

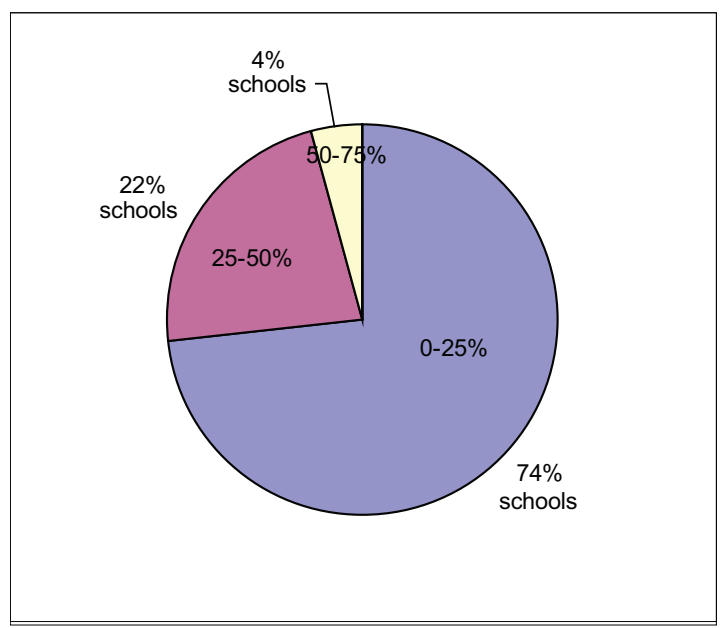

OMFS

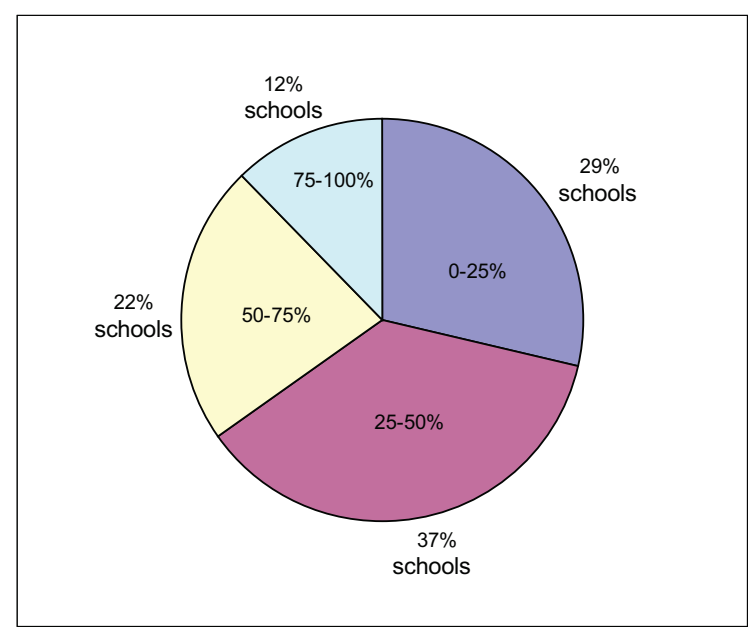

Figure 5. Percentage of patients referred to Endodontics and Oral and Maxillofacial Surgery from dental school urgent care services

\section{Indigent Care}

The survey found that 30.6 percent of dental school urgent care services address indigent care, another 30.6 percent somewhat address indigent care, and 20.4 percent do not address indigent care at all. Forty-nine percent of schools accept Medicaid as payment. Most schools reported that no patients with odontogenic infections, cellulitis, or traumatic injuries are turned away and that the school bears the cost of treating these patients in most cases.

Opinions about a dental school's responsibility to provide indigent care are varied, yet homogenous on some basic levels. While some schools refer patients without the ability to pay to free or low-cost clinics, the general consensus is that dental schools are responsible for the treatment of any patient presenting with swelling or orofacial trauma. Some indicated that treatment should be extended to those in any type of acute pain, regardless of finances. Providing indigent care is a critical aspect of some schools' missions, and these schools asserted that all dental schools should share the responsibility of treating the underserved just as any dental practice should. One school commented that treating indigent patients is a good source of clinical experiences for D.D.S. students. Others clearly stated that restrictions must exist for providing indigent care in a dental school environment due to budgetary constraints. Many mentioned a need for external funding and grants and suggested that the state bear the financial burden of indigent care.

\section{Discussion}

The survey responses demonstrate that dental schools have varied approaches to dental emergency education. This may be related to the different needs of the local community as well as the philosophy of the particular state and the dental school budget for urgent care services.

\section{Operation}

Schools seem to give patients flexibility by offering care to both walk-in patients and those with appointments. About three-quarters of dental schools operate urgent care services thirty or more hours per week, with most remaining open during school breaks and holidays, providing needed care to their surrounding communities. In almost 60 percent of these services available during breaks and holidays, volunteer students (paid or nonpaid) are part of the 
staff. This not only helps the urgent care service in rendering treatment, but also provides the students with valuable dental emergency experience.

General Dentistry is the most responsible and represented department in school urgent care services, demonstrating a shift from Oral Diagnosis/Oral Medicine as was the case in $1982 .{ }^{4}$ Interestingly, Dental Public Health has no representation. Pediatric Dentistry is represented only in one-tenth of clinics, most likely due to pediatric emergencies being handled differently and not always within the urgent care service. The separation of adult and child dental emergency care may prevent D.D.S. students rotating through the urgent care service from receiving adequate exposure to pediatric emergencies. Because all pediatric emergencies are handled by residents or specialists only, exposure in the urgent care service is limited to adult emergency care. As a consequence, students at many schools can receive experience in urgent care for children only if the Pediatric Dentistry department offers its own emergency rotations.

\section{Treatment}

Most urgent care services attempt to simulate a general dentist's office in private practice. All objective data is collected, and then the diagnosis and treatment recommendation are made. Routine treatments-largely sedative fillings, pulpotomies/pulpectomies, and provisional restorations - are provided in the urgent care service; specialist care referrals are made for more complicated cases. Schools indicate that a key goal of the learning experience is to help students understand the limits of a traditional general dentist when treating emergencies. Students must be able to determine which treatment model - triage and referral versus triage and treatment-is appropriate in each individual case. ${ }^{5}$

\section{Integration into D.D.S. Curriculum}

Dental emergencies for active patients are handled evenly by both the assigned D.D.S. student and the urgent care service. Generally, during the normal course of the semester, the assigned student handles any of his or her patients' emergencies, and the urgent care service acts only as a back-up for when the student is on vacation, on external rotation, or sick. The concept that a dental student is entirely responsible for a patient, including emergency care, approaches a true comprehensive care model. In addition, restorative emergencies often teach the student how to produce better quality work. Han- dling multiple patients in one clinic session when adding an emergency patient to the schedule gives the student a real-world private practice experience. Of course, this may be realistic and feasible for only senior dental students.

The average number of days a student spends in urgent care is 14.89 , with generally five or more students providing care in a single clinic session. Generally, the urgent care service is considered a senior rotation at dental schools, with significant participation of junior students and minor sophomore and freshman participation (observation only). This likely has to do with the amount of critical thinking and speed required to cope with emergency situations.

The majority of schools ( 65.3 percent) reported that no clinical or didactic assessments are required of students when they rotate through the urgent care service. Moreover, only 30.6 percent of schools require students to complete a competency exam for the urgent care service. Clearly, emergency education needs to be more integral to a dental student's learning experience. Poor access to care and recent natural disasters mandate a stronger emphasis on dental emergency education within the D.D.S. curriculum because application of such information-seeking skills is required in times of catastrophe. ${ }^{6}$

\section{Demographics}

School urgent care services see varying numbers of walk-in patients or patients not of record most likely due to area population, dental resources, and the schools' missions and philosophies regarding indigent care.

The majority of dental schools reported that urgent care patients are referred to Endodontics less than 25 percent of the time, whereas the percentage of Oral and Maxillofacial Surgery (OMFS) referrals differs greatly among urgent care services. Referrals to Endodontics depend on patient acceptance of a more extensive and expensive treatment plan. Thus, financial considerations may influence patients to go to OMFS for an extraction rather than to Endodontics for root canal therapy. Some urgent care services perform extractions in the department, decreasing the need for OMFS referrals in those schools.

\section{Indigent Care}

The philosophies of dental schools regarding indigent care are varied. Half of the dental schools do not accept Medicaid. While many schools reported 
they do not turn away patients with swelling or orofacial trauma, some schools admitted to ignoring the ethical obligation and responsibility of treating these patients. External funding would encourage more dental schools to provide more indigent emergency dental care, giving students increased awareness of this population's needs. In addition, given current issues regarding access to care, increased funding would help address some of the pressing dental needs in the community at large.

\section{Conclusion}

We hypothesized that dental emergency education is likely the most variable component of the dental curriculum. Using a survey distributed to the directors of urgent care services, we attempted to characterize these differences with the goal of guiding the development of a more formalized curriculum for this area of care. Importantly, the survey response rate of 88 percent allows the results to accurately reflect the current state of dental emergency education in U.S. dental schools.

Our results demonstrate that, although triage is an important aspect of the delivery of urgent care in the dental setting, substantial treatment is also provided on-site, with an emphasis on sedative fillings, pulpotomies/pulpectomies, and provisional restorations.

Pediatric emergency treatment is not adequately addressed in the predoctoral setting. This area warrants improvement in all dental schools because the typical U.S. dental school graduate does not receive substantive pediatric dental emergency experience and will confront cases requiring this type of management shortly after graduation if entering private practice.

The urgent care experience could be broadened to integrate students into the process at an earlier stage in their education. This would give them a better understanding of acute dental needs, enhancing the provision of care for their own patients in the dental school as well as those treated on external rotations.

Over 65 percent of responding schools reported that they do not overtly evaluate the students' performance during urgent care rotations. We suggest that the academic base of dental schools be broadened to address this critical care issue more rigorously.

From a public health perspective, more external funding is required for schools to adequately and ethically address the urgent dental care needs of indigent populations. Exposure of D.D.S. students to the needs of the indigent population increases their sensitivity as they enter private practice, ultimately encouraging them to participate in the care of these patients.

\section{Acknowledgments}

The authors would like to thank Judy Dow and Andrea Hall for their assistance.

\section{REFERENCES}

1. Sharav Y, Galili D, Sciaky I. Emergency patients: source for learning oral diagnosis. J Dent Educ 1973;37(6): 31-4.

2. Gates RL, Durchslag DG. Triage in the management of emergency patients. J Dent Educ 1978;42(6):314-5.

3. Bauman GH, Creamer TJ, Cohen LA, Hasler JF. Afterhours emergency policies at U.S. dental schools. J Dent Educ 1998;62(8):584-6.

4. Ferraro EF, McQuiness JW, Lee MM. Emergency dental care in dental education. J Dent Educ 1982;46(8):504-5.

5. Comer RW, Laswell HR, Pashley EL, Dodge W. Implications and future challenges. J Dent Educ 2000;64(1): 29-33.

6. More FG, Phelan J, Boylan R, Glotzer D, Psoter W, Robbins $\mathrm{M}$, et al. Predoctoral dental school curriculum for catastrophe preparedness. J Dent Educ 2004;68(8):851-8. 